\title{
TÉCNICA E CUSTO PARA O ENSACAMENTO DE FRUTOS DE PÊRA JAPONESA ${ }^{1}$
}

\author{
IVAN DAGOBERTO FAORO
}

RESUMO - A técnica de ensacamento da pêra japonesa, além de evitar a poluição ambiental causada por defensivos agrícolas, ainda proporciona melhoria na qualidade organoléptica dos frutos, reduzindo os danos provocados por mosca-das-frutas e grafolita. No presente trabalho, utilizaram-se as cultivares Hosui e Nijisseiki, cujos frutos foram ensacados logo após o raleio para evitar-se o desenvolvimento do "russeting" e o contato com insetos. Para a 'Housui', foi necessário um só ensacamento, ao custo de R \$ 4.075,00/ha, considerando 110.000 frutos/ha. Já para a 'Nijisseiki', são necessários dois ensacamentos, resultando um custo de $\mathrm{R} \$ 4.118,00 / \mathrm{ha}$, considerando-se 73.370 frutos/ha. O custo aproximado do ensacamento em 'Housui' foi de R \$ 0,04/fruto e em 'Nijisseiki', R \$ 0,06/fruto. Mesmo sendo maior o custo do ensacamento para a 'Nijisseiki', esta cultivar obteve preços comerciais inferiores ao da 'Housui' no mercado brasileiro. O aumento do custo de produção devido ao ensacamento é passível de ser assimilado pelo produtor, desde que obtenha frutos de maior qualidade para, assim, vender os frutos ensacados com preços superiores.

Termos para indexação: Pyrus, pêra japonesa, ensacamento, técnica, custo

\section{TECHNIQUE AND BAGGING COST OF NASHI FRUIT PEARS}

Abstract - The bagging technique of Nashi pears not only insures good environmental effects by avoiding inseticide use, but also improves the flavor of fruits by decreasing the damages caused by fruit-fly and oriental fruit moth. This study was carried out with the cultivars Housui and Nijisseiki. The fruits were bagged just after thinning in order to avoid the development of russeting and to protect them against insects attack. For cv. Housui a single bag was enough. The total cost of bagging was R $\$ 4,075.00 /$ ha, considering 110.000 fruits/ha. For cv. Nijisseiki it was necessary to use a double bagging, with a total cost of $\mathrm{R} \$ 4,188.00 /$ ha to protect 73.370 fruits/ha. The estimated bagging cost per fruit was $\mathrm{R} \$ 0.04$ for cv. Housui and $\mathrm{R} \$ 0.06$ for cv. Nijisseiki. Not only the bagging cost of 'Nijisseiki' fruits was higher compared to 'Housui' fruits, but also the price of 'Nijisseiki' is being lower at the Brazilian market as compared to 'Housui' price. The higher production cost by using fruit bagging should be assimilated by fruit growers considering it improves fruit quality that insures better price at market place.

Index terms: Pyrus, Nashi pears, bagging, techniques, cost

A técnica do ensacamento dos frutos vem sendo preconizada há muitos anos pela pesquisa e já é utilizada por alguns produtores. No caso da pêra japonesa, as cultivares de película verde-amarelada, como a 'Nijisseiki', exigem o ensacamento; caso contrário, os frutos desenvolvem rugosidade ("russeting") e ficam com aparência comercial indesejável. Já nas cultivares de película marrom, como a 'Housui' e 'Kousui', o ensacamento não é necessário. No entanto, alguns produtores estão realizando esta prática, com a qual existe a possibilidade de eliminar ou reduzir o uso de inseticidas e fungicidas. Isso pode facilitar, no futuro, aliado a outras pesquisas, a própria produção de pêra orgânica.

O ensacamento de frutos da pêra japonesa deve ser realizado para: a) evitar danos de insetos, principalmente da mosca-das-frutas (Anastrepha fraterculus) e da grafolita (Grapholita molesta); b)controlar doenças, especialmente a Pinta Preta (Alternaria spp.) na 'Nijisseiki'; c) reduzir ou evitar a rugosidade ("russeting"), principalmente em 'Nijisseiki' e suas mutações (Kotobuki et al., 1992); d) obter frutos de melhor aparência e película mais lisa; e) reduzir a quantidade de defensivos aplicados ou mesmo a rugosidade eventualmente ocasionada por algum defensivo (White et al., 1990); f) evitar danos ocasionados por pássaros; g) amenizar eventuais danos ocasionados por chuvas leves de granizo (Faoro, 2000).

$\mathrm{O}$ raleio da pêra é feito manualmente, sendo mantido um fruto.racimo ${ }^{-1}$ espaçado um do outro cerca de $20 \mathrm{~cm}$. Deve-se deixar somente o $3^{\circ}$ ou $4^{\circ}$ fruto do racimo, já que as primeiras flores tendem a produzir frutos mais achatados e as últimas produzem frutos mais compridos (Uraki et al., 1982).

Na opção de ensacamento dos frutos, deve-se levar em consideração o aumento da demanda da mão-de-obra, sendo que, para 1 hectare, são necessários cerca de 1.680 horas (White et al, 1990) ou 954 horas para Nijisseiki, no Japão.

$\mathrm{Na}$ ausência de ensacamento, aproximadamente um mês após a polinização, os frutos da pêra japonesa já desenvolvem uma cutícula, formando então a rugosidade. Na terceira semana após a polinização, a alta umidade ou mesmo alguns fungicidas também podem induzir a formação de rugosidade. A alta umidade, provavelmente, é o maior agente causal da rugosidade dos frutos. Existe correlação entre a rugosidade e o número de horas de exposição à alta umidade e à precipitação, especialmente entre o $16^{\circ}$ e $20^{\circ}$ dia após a plena floração. Nesse período, há intenso crescimento do fruto e, em conseqüência, ocorrem aberturas na cutícula, favorecendo a penetração da água até as células epidérmicas, que absorvem esta água e, por pressão de turgência, se rompem. Assim, devido à oxidação de seu conteúdo celular, adquirem a coloração marrom-bronzeada, característica da rugosidade (Gil, 1989). Por isso, o fruto deve ser ensacado cerca de três a quatro semanas após a polinização, quando o pistilo já está firme e o raleio já foi realizado.

Conforme a cor da película dos frutos, o ensacamento pode ser realizado em uma ou duas etapas:

A)Para frutos com película amarela (ex: 'Nijisseiki'), é dividido em duas etapas: primeiramente, são colocados os sacos pequenos $(7,0 \mathrm{x}$ $10,0 \mathrm{~cm})$ e, posteriormente, os sacos grandes $(13,0 \times 22,0 \mathrm{~cm})$. Os sacos pequenos são colocados a partir da terceira semana após a plena floração e após o raleio, quando os frutos possuem cerca de $1,0 \mathrm{~cm}$ de diâmetro. $\mathrm{O}$ tipo de saco pequeno mais utilizado é o de papel manteiga transparente, de preferência parafinado, pois proporciona pouco aumento da temperatura interna. É citado que uma pessoa treinada realiza cerca de 2.000 a 5.000 ensacamentos/dia (Uraki, 1982). Tem-se observado em Santa Catarina que os frutos da cultivar Nijisseiki, por apresentarem pedicelos curtos, devido à menor adaptação às condições climáticas, ficam escondidos sob as folhas, dificultando o ensacamento. Por isso, o rendimento por área fica prejudicado, situando-se entre 1.000 e 1.500 frutos ensacados/dia/homem. Pouco antes de os sacos pequenos apresentarem risco de rasgarem devido ao crescimento do fruto, o que ocorre cerca de dois meses após a plena floração, são colocados os sacos grandes sobre os sacos pequenos. Ambos ficam até a colheita. Os sacos grandes podem ter dupla camada de papel, sendo que o saco da camada interna pode conter inseticida e fungicida (Uraki, 1982). Preferencialmente, devem ser utilizados sacos de camada dupla e coloração interna amarelada e cor externa bege-escura, ou sacos de papel Kraft de coloração marrom-escura e não transparente. Uma pessoa treinada ensaca cerca de 1.000 a 1.200 frutos/dia.

\footnotetext{
${ }^{1}$ (Trabalho 189/2002). Recebido: 16/12/2002. Aceito para publicação: 04/07/2003.

${ }^{2}$ Eng.-Agr ${ }^{\circ}$, M.Sc., Cart.Prof.no 4.699-D, CREA-SC, EPAGRI, Estação Experimental de Caçador: Bairro Bom Sucesso, Estrada Geral s/n, e-mail: faoro@ epagri.rctsc.br, Caixa Postal 591, Tel(0xx49)663-0211, Fax(0xx49)663-3211, 89500-000, Caçador-SC.
} 
B) Para frutos de película marrom (ex: 'Housui' e 'Kousui'): neste caso, somente são utilizados sacos grandes de papel Kraft de cor marrom, colocados cerca de um mês após o final da floração, quando os frutos possuem diâmetro superior a 2,5 3,0cm. Os sacos são deixados até a colheita.

Para facilitar o processo de ensacamento, os sacos pequenos devem ser previamente confeccionados com fita adesiva dupla para que se possa fechá-los rapidamente no campo, durante o ensacamento dos frutos. Os sacos grandes devem receber previamente um arame fino preso por um pequeno pedaço de fita adesiva na parte superior, para também facilitar o fechamento a campo. É importante que os sacos possuam um pequeno corte em seu fundo, para permitir o escorrimento d'água. Em virtude de os frutos de 'Housui' e 'Nijisseiki' serem maiores que o da 'Kousui', os sacos também devem ser maiores.

Um fator de suma importância a ser analisado é a redução da quantidade de agrotóxicos utilizados no pomar, principalmente de inseticidas. A redução ou mesmo eliminação dos inseticidas devido ao ensacamento dos frutos deve-se ao controle químico desnecessário da mosca-das-frutas e da grafolita. Em pomares comerciais onde é realizado o ensacamento, o dano ocasionado por insetos e podridões, confor- me o ano, tem variado entre 1,1 e $3,8 \%$ dos frutos produzidos (Faoro e Yasunobu, 2001). Na ausência do ensacamento e do controle químico, há risco de os danos atingirem a totalidade dos frutos.

Financeiramente, o ensacamento ainda é uma prática que proporciona maiores gastos que a aplicação de inseticidas e fungicidas. Nas Tabelas 1 e 2, são apresentados os custos de confecção de sacos pequenos e grandes, e do ensacamento, baseados em informações obtidas com produtores dos municípios de Frei Rogério e Caçador, que já estão adotando esta prática, além da experiência da pesquisa. Para a 'Housui', para a qual é necessário um ensacamento, mas a quantidade de frutos/ha é maior, o custo estimado é de $\mathrm{R} \$ 4.075,50 / \mathrm{ha}$ ou, aproximadamente, R \$ 0,04/fruto (Tabela 1). Já para a 'Nijisseiki', em função da necessidade de dois ensacamentos, o custo é maior e situa-se em $\mathrm{R} \$$ $4.118,00 /$ ha ou, aproximadamente, $\mathrm{R} \$ 0,06 /$ fruto (Tabela 2).

O ensacamento dos frutos reduz a poluição ambiental, melhora a apresentação dos frutos e reduz o risco de dano causado pela moscadas-frutas e pela grafolita. $\mathrm{O}$ aumento do custo de produção devido ao ensacamento é passível de ser assimilado pelo produtor, desde que obtenha frutos de qualidade e com melhores preços junto aos consumidores.

TABELA 1- Estimativa do custo para o ensacamento dos frutos de 1 (um) hectare de pêra japonesa cv. Housui, em Santa Catarina, maio/2002.

\begin{tabular}{l|cccc}
\hline \multicolumn{1}{c|}{ Discriminação } & Item & Quantidade & Valor unitário (R\$) & Valor total (R\$) \\
\hline \multicolumn{1}{c}{ Mão-de-obra } & Ensacamento & 110 dias/h & 18,00 & $1.980,00$ \\
\hline & Sacos papel & 110.000 & $14,50 /$ milheiro & $1.595,00$ \\
& Arame extrudado & $25 \mathrm{~kg}$ & 13,00 & 325,00 \\
\multicolumn{1}{c}{ Sacos grandes } & Etiqueta adesiva & 66 rolos & 0,75 & 49,50 \\
& Colocação fita & 7 dias/H & 18,00 & 126,00 \\
\hline Custo total/ha & & & & $4.075,50$ \\
$\mathrm{~N}^{\mathbf{0}}$ frutos/ha & & & & 110.000 \\
Custo ensacamento/fruto $(\mathrm{R} \$)$ & & & & 0,037 \\
\hline
\end{tabular}

Nota: dias/H: dias homem. Considerou-se a produtividade de 30 t/ha.

TABELA 2 - Estimativa do custo para a confecção e o ensacamento dos frutos de 1 (um) hectare de pêra japonesa cv. Nijisseiki, em Santa Catarina, maio/2002.

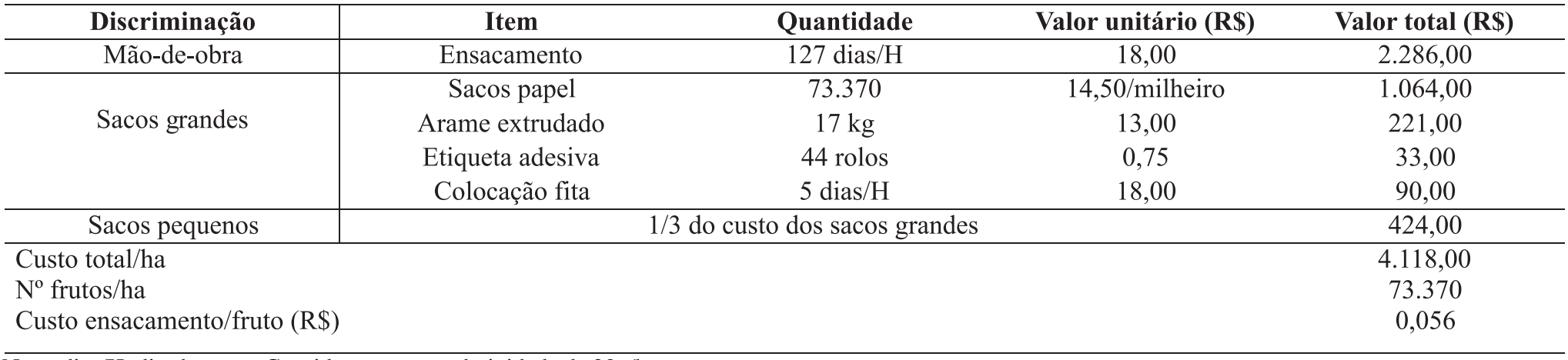

Nota: dias/H: dias homem. Considerou-se a produtividade de 20 t/ha.

\section{REFERÊNCIASBIBLIOGRÁFICAS}

FAORO, I.D. Raleio e ensacamento. In: CURSO SOBRE A CULTURA DA PEREIRA, 2., 2000, Caçador. Trabalhos apresentados... Caçador: Epagri/Jica, 2000. p.47-52.

FAORO, I.D.; YASUNOBU, Y. Investigação dos fatores de necrose de gemas e seu controle. In: PROJETO de Pesquisa em Horticultura para Pequenos Produtores no Sul do Brasil. São Joaquim, SC: EPAGRI/JICA/EMBRAPA, 2001.(Relatório anual 2000-2001).

GIL, S.G.F La rugosidade o ruginosidade ("russet") de la fruta. Revista Frutícola, v.10, n.2, p.57-62, 1989.
KOTOBUKI,K.; SANADA,T.; NISHIDA,T.; FUJITA,H.; IKEDA,F. 'Gold Nijisseiki, a new japanese pear mutant cultivar resistant to black spot disease induced by chronic irradiation of gamma-rays. Bulletim of the National Institute of Agrobiological Resources, n.7, p.105$129,1992$.

URAKI,M. The culture of Nijisseiki pear in Tottori prefecture, Japan. In: VAN DER ZWEET,T.; CHILDERS,N.F. (Eds.) The pear. Gainesville: Horticultural Publications, 1982.p. 77-82.

WHITE,A.; CRANWELL,D.; DREWITT,B.; HALE,C.; LALLU,N.; MARSH,K.; WALKER,J. Nashi, asian pear in New Zealand. Wellington: DSIR Publishing, 1990. 85p. 